\title{
OXIDATIVE STRESS IN ACUTE CORONARY SYNDROME
}

\author{
P. Srilakshmi1 ${ }^{1}$ D. Swetha ${ }^{2}$, K. Rambabu ${ }^{3}$
}

\section{HOW TO CITE THIS ARTICLE:}

P. Srilakshmi, D. Swetha, K. Rambabu. "Oxidative Stress in Acute Coronary Syndrome". Journal of Evolution of Medical and Dental Sciences 2015; Vol. 4, Issue 87, October 29; Page: 15201-15208,

DOI: $0.14260 /$ jemds $/ 2015 / 2160$

\begin{abstract}
Oxidative stress and free radicals are known to have important roles in the development of atherosclerosis, which is the underlying cause of acute coronary syndrome (ACS). Malondialdehyde (MDA), a carbonile group produced during lipid peroxidation, is used widely in determining oxidative stress. This study of oxidative stress is in terms of Malondialdehyde (MDA) and total antioxidant capacity (TAC). MATERIALS AND METHODS: Study group comprised of 114 patients diagnosed as having ACS based on clinical and bio-chemical criteria. Control group included 66 age and sex matched subjects (Non ACS cases) using the same criteria. RESULTS: In this study, significant increase of mean values of serum MDA and significant decrease in TAC level was observed in ACS cases when compared with controls. CONCLUSION: Oxidative stress is markedly observed in ACS cases, MDA increased and TAC is decreased.
\end{abstract}

KEYWORDS: Oxidative stress, ACS, MDA, TAC.

INTRODUCTION: Antioxidant status is a critical tool for assessing redox status, which is defined as the balance between oxidants (Free radicals and other reactive species) and antioxidants.[1,2] Oxidative stress is described as impairment of equilibrium between prooxidant and antioxidant systems resulting in excess free radicals or decreased effective concentration of antioxidants or both. ${ }^{[3]}$ Free radical is defined as a species that contains one or more unpaired electrons in its outer orbital, which renders it considerable degree of reactivity. ${ }^{[4-6]}$

\section{SOURCES OF FREE RADICALS:}

Endogenous: These endogenous radical production ways account for most of the oxidants produced by cells. Additional endogenous sources are neutrophils, eosinophils, macrophages, tissue damage, and mitochondrial electron transport chain and ischemia-reperfusion injury.[7,8]

Exogenous: Exogenously free radicals are formed by cigarette smoke, ionizing radiation, pollutants, organic solvents, anesthetic gases, hyperoxic environments and pesticides.[6,9,10] Free radicals and related reactive species are mainly derived from oxygen (Reactive oxygen species/ROS) and nitrogen (Reactive nitrogen species/RNS), and are generated in humans by various endogenous systems, exposure to different physicochemical conditions or pathophysiological states.[11]

In addition to traditional risk factors, oxidative stress has been regarded as one of the most important contributor to the progression of atherosclerosis.[12] Increased lipid peroxidation.[13] is thought to be a consequence of oxidative stress, which occurs when the dynamic balance between prooxidant and antioxidant mechanism is impaired.[14]

So, oxidative stress and lipid peroxidation are involved in the pathogenesis of atherosclerosis.[15] Jean-Claude Tardif.[16] observed that oxidative stress appears to be important in both the early and later stages of the atherosclerotic process. Evidence suggests that reactive species may play important role in the pathogenesis of ACS.[17,18] 


\section{ORIGINAL ARTICLE}

There is evidence that antioxidants can protect against free radical defense, which is responsible for reperfusion-induced damage and lipid peroxidation, and may thereby inhibit thrombosis, myocardial damage and arrhythmias during ACS.[19,20] Antioxidant status is a critical tool for assessing redox status, which is defined as the balance between oxidants (free radicals and other reactive species) and antioxidants.[19,21,22]

Findings suggest that increased oxidative stress may be an important mechanism for impaired endothelial function in patients with atherosclerosis. Endothelial dysfunction and increased vascular oxidative stress predict the risk of cardiovascular events in patients with ACS.

Coronary artery disease (CAD) is the leading cause of death and is a major health burden worldwide. One fifth of all deaths are due to CAD. By the year 2020, it will account for one third of all deaths. There are an estimated 45 million patients of CAD in India.

Early and accurate diagnosis of coronary disease is very essential as it is associated with significant morbidity and mortality. Atherosclerosis is underlying cause of CAD. CAD is a condition in which there is an inadequate supply of blood and oxygen to a portion of the myocardium. The clinical spectrum of CAD is stable angina (SA), unstable angina (UA) and myocardial infarction (MI).[23] ACS includes UA and MI.[24]

The frequency of ACS is extremely high among Indians; India has the highest burden of ACS in the world. The rising incidence of ACS in Indians may be associated with changes in the lifestyle, the westernization of the food practices, the growing prevalence of diabetes mellitus and probably genetic factors. ${ }^{[25]}$

MATERIALS AND METHODS: The study was conducted in the department of biochemistry, Mamata Medical College and General Hospital, Khammam, Andhra Pradesh, India. The patients attending outpatient and wards of cardiology and general medicine departments of hospital and local cardiac centers were included in this study.

All subjects were informed about the study and written informed consent was obtained from the patients enrolled. The study was approved by the institutional ethical committee. Antioxidant status was evaluated by MDA and TAC. Lipid peroxidation product, MDA was measured as an index of free radical production.

MDA is determined as Thiobarbituric acid reactive substances (TBARS) and over all antioxidant capacity, TAC measured as Ferric reducing ability of Plasma (FRAP). MDA and FRAP are expressed as $\mathrm{m} \mathrm{mol} / \mathrm{L}$.

Study Design: Cross-sectional comparative study.

Statistical Analysis was done using statistical analysis of software (SAS), version 9.3. The results are expressed as mean \pm standard deviation (SD). $\mathrm{P}<0.05$ was considered statistically significant.

Subjects: Study group comprised of 114(47 were without risk and 67were with risk) patients diagnosed as having ACS based on clinical and bio-chemical criteria using ECG, echocardiogram, cardiac biomarkers (Myocardial enzymes and troponin) and tread meal test (TMT). 


\section{ORIGINAL ARTICLE}

\section{Inclusion Criteria:}

- Subjects in the age group of 30-50.

- Subjects with risk factors DM, HTN and smoking.

- Subjects with DM, assessed based on history and WHO criteria.

- Subjects with HTN, assessed based on history and JNC-7 criteria.

\section{Exclusion Criteria:}

- Alcoholics.

- Subjects with of past history of ACS.

- Subjects on antioxidant supplementation.

Controls: 66 sex and age matched subjects were recruited as control group (non ACS cases) using the same criteria. Out of 66 , thirty were without risk and thirty six were with risk.

\section{RESULTS:}

Controls v/s ACS cases: In our study, mean MDA value was significantly increased and TAC was decreased in ACS cases than controls (Table 1a).

Controls without risk v/s ACS without risk: Significant increase of mean MDA values were observed in ACS without risk was compared with controls without risk. Significant decrease of mean TAC values were observed in ACS without risk was compared with controls without risk (Table 1b).

Controls with risk v/s ACS with risk: Significant increase of mean MDA and in ACS cases with risk compared with controls with risk. Mean TAC were significantly decreased in ACS with risk than controls with risk (Table 1c).

ACS with risk v/s ACS without risk: Non-significant increase in mean values was observed in MDA levels and non-significant decrease in TAC was observed in ACS cases with risk when compared with those without risk (Table 1d).

Total ACS cases, ACS with risk and ACS without risk: The correlation between TAC with MDA was not significant in Total ACS cases, ACS with risk and ACS without risk (Table 2a, Table 2b, and Table 2c).

UA v/s MI: In the spectrum of ACS (UA and MI) mean MDA was increased and TAC was decreased in UA and MI respectively (Table 3a). The correlation between TAC with MDA was not significant in UA and MI (Table 3b and Table 3c).

\section{DISCUSSION:}

The role of oxidative stress in atherosclerosis: In the present study mean MDA value was significantly increased and TAC was decreased in ACS cases than controls. The results are in accordance with the study done by Ali Movahed et al.[26] and Murat Aydın et al.[27] In total ACS cases (UA and MI) mean MDA values have shown incremental increase and TAC has shown incremental decrease. Similar results were reported by some studies.[28,29]

Higher MDA and lower TAC levels were observed in the presence of risk factors. These results 


\section{ORIGINAL ARTICLE}

were in accordance with Madhur gupta et al.[30] Neela Patil et al.[31] Margarete Dulce Bagatini et al..[32] and Mudassir Ahmad Khan et al.[33] Endothelial function is impaired in the earlier stages of atherogenesis and is strongly correlated with several risk factors.

Endothelial dysfunction predisposes to long-term atherosclerotic lesions and has been proposed as an important diagnostic and prognostic factor for coronary syndromes.[34] The production of free radicals is believed to induce endothelial dysfunction which is an initial step in atherogenesis. Oxidative stress leads to oxidation of LDL (ox-LDL), whose uptake by macrophages is easier than non-oxidized lipoproteins. The main sources of oxidative substances are macrophages and SMCs. ${ }^{[35]}$ Hypercholesterolemia stimulates the production of $\mathrm{O}_{2}{ }^{-}$from smooth muscle vessels an event that leads to increased oxidation of LDL.

Further reduction of endothelial-produced nitric oxide presence $\mathrm{O}_{2}{ }^{-}$cause the endothelial dysfunction. The increased production of ROS reduces the production and bioavailability of nitric oxide, leads to vasoconstriction, platelet aggregation and adhesion of neutrophils to the endothelium. ${ }^{6,36]}$

Atherosclerosis results due to oxidative modification of LDL in the arterial wall by ROS. Evidence suggests that common risk factors for atherosclerosis increase the risk of production of ROS. ROS arise from endothelial cells, SMCs and also adventitial cells.

Thus hypercholesterolemia, diabetes, arterial HTN, smoking and age increases the production of ROS.[37] These risk factors are responsible for the triggering of proliferation and migration of SMCs, the apoptosis of endothelial cells, and oxidation of lipids, activation of metalloproteinases and alteration of vasomotor activity.[38,39]

Antioxidant status, which is a balance between oxidants and antioxidants, also has been implicated in pathogenesis of atherosclerosis. ROS causes oxidative modification of LDL. Hypercholesterolemia itself can increase ROS generation. Free radicals induce endothelial dysfunction, which again increases ROS production.

Together with decrease in the antioxidant capacity ROS will potentiate the risk. Endothelial dysfunction contributes to further progress of atherosclerosis leading eventually to complex atherosclerotic lesions.[24,40] HTN, DM, IR, hypercholesterolemia and smoking causes the production of ROS from endothelium. Free radicals induce endothelial dysfunction which again increases ROS production.[10] We have observed increased lipid peroxidation and decreased antioxidant capacity in total ACS cases.

CONCLUSION: Increased lipid peroxidation and decreased TAC was observed in ACS cases. So, antioxidant status was altered more in MI than UA. Higher MDA and lower TAC levels were observed in the presence of risk factors.

\begin{tabular}{|c|c|c|c|}
\hline Parameter & $\begin{array}{c}\text { Mean } \pm \text { SD } \\
\text { (Controls) }\end{array}$ & $\begin{array}{c}\text { Mean } \pm \text { SD } \\
\text { (Cases) }\end{array}$ & P-value \\
\hline MDA & $1.5394 \pm 0.4163$ & $4.8444 \pm 1.5294$ & $<0.0001$ \\
\hline TAC & $0.9594 \pm 0.2701$ & $0.5936 \pm 0.1813$ & $<0.0001$ \\
\hline \multicolumn{4}{|c|}{ Table 1a: Mean \pm SD of biochemical parameters of } \\
Controls (66) and ACS cases (114) \\
\hline
\end{tabular}




\section{ORIGINAL ARTICLE}

\begin{tabular}{|c|c|c|l|}
\hline & $\begin{array}{c}\text { Mean } \pm \text { SD } \\
\text { (Controls without risk) }\end{array}$ & $\begin{array}{c}\text { Mean } \pm \text { SD } \\
\text { (ACS without risk) }\end{array}$ & P-value \\
\hline MDA & $1.33 \pm 0.27$ & $4.62 \pm 1.58$ & $<0.0001$ \\
\hline TAC & $1.036 \pm 0.289$ & $0.61 \pm 0.15$ & $<0.0001$ \\
\hline \multicolumn{3}{|c|}{ Table 1b: Mean \pm SD of biochemical parameters of } \\
Controls without risk (30) vs ACS without risk (47)
\end{tabular}

\begin{tabular}{|c|c|c|c|}
\hline Parameter & $\begin{array}{c}\text { Mean } \pm \text { SD } \\
\text { (Controls with risk) }\end{array}$ & $\begin{array}{c}\text { Mean } \pm \text { SD } \\
\text { (ACS with risk) }\end{array}$ & P-value \\
\hline MDA & $1.70694 \pm 0.44363$ & $5.00134 \pm 1.47731$ & $<0.0001$ \\
\hline TAC & $0.89556 \pm 0.23843$ & $0.58015 \pm 0.200012$ & $<0.0001$ \\
\hline \multicolumn{4}{|c|}{$\begin{array}{c}\text { Table 1c: } \text { Mean } \pm \text { SD of biochemical parameters of } \\
\text { controls with risk (36) vs ACS with risk (67) }\end{array}$} \\
\hline
\end{tabular}

\begin{tabular}{|c|c|c|c|}
\hline Parameter & $\begin{array}{c}\text { Mean } \pm \text { SD } \\
\text { (ACS without risk) }\end{array}$ & $\begin{array}{c}\text { Mean } \pm \text { SD } \\
\text { (ACS with risk) }\end{array}$ & P-value \\
\hline MDA & $4.6209 \pm 1.5900$ & $5.0013 \pm 1.4773$ & 0.1923 \\
\hline TAC & $0.6117 \pm 0.1508$ & $0.5801 \pm 0.2001$ & 0.3628 \\
\hline
\end{tabular}

Table 1d: Mean \pm SD of biochemical parameters of ACS without risk (47) vs ACS with risk (67)

\begin{tabular}{|c|c|c|}
\hline Variable & TAC & MDA \\
\hline TAC & 1 & $-0.11 \mathrm{NS}$ \\
\hline MDA & & 1 \\
\hline \multicolumn{2}{|c|}{ Table 2a: Correlations of biochemical variables in ACS } \\
\hline
\end{tabular}

\begin{tabular}{|c|c|c|}
\hline Variable & TAC & MDA \\
\hline TAC & 1 & $-0.04 \mathrm{NS}$ \\
\hline MDA & & 1 \\
\hline $\begin{array}{c}\text { Table 2b: Correlations of biochemical } \\
\text { variables in ACS without risk }\end{array}$ \\
\hline
\end{tabular}

\begin{tabular}{|c|c|c|}
\hline Variable & TAC & MDA \\
\hline TAC & 1 & $-0.13 \mathrm{NS}$ \\
\hline MDA & & 1 \\
\hline \multicolumn{2}{|c|}{ Table 2c: Correlations of biochemical variables in ACS with risk } \\
\hline
\end{tabular}

\begin{tabular}{|c|c|c|c|}
\hline & $\begin{array}{c}\text { Mean } \pm \text { SD } \\
\text { (UA) }\end{array}$ & $\begin{array}{c}\text { Mean } \pm \text { SD } \\
\text { (MI) }\end{array}$ & P-value \\
\hline MDA & $4.22 \pm 1.61$ & $5.08 \pm 1.43$ & 0.0063 \\
\hline TAC & $0.64 \pm 0.22$ & $0.57 \pm 0.15$ & 0.0537 \\
\hline Table 3a: Mean \pm SD of biochemical parameters of UA (32) vs MI (82) \\
\hline
\end{tabular}




\section{ORIGINAL ARTICLE}

\begin{tabular}{|c|c|c|}
\hline Variable & TAC & MDA \\
\hline TAC & 1 & $-0.03 \mathrm{NS}$ \\
\hline MDA & & 1 \\
\hline Table $3 \boldsymbol{b}$ : Correlations of biochemical variables in $\boldsymbol{U A}$ \\
\hline
\end{tabular}

\begin{tabular}{|c|c|c|}
\hline Variable & TAC & MDA \\
\hline TAC & 1 & $-0.08 \mathrm{NS}$ \\
\hline MDA & & 1 \\
\hline \multicolumn{2}{|c|}{ Table 3c: Correlations of biochemical variables in MI } \\
\hline
\end{tabular}

\section{REFERENCES:}

1. Giselli A, Serafini M, Natella F, and Scaccini C, Total antioxidant capacity as a tool assesses redox status: critical view and experimental data. Free Rad. Biol. Med. 2000; 29:1106-1114.

2. Palanisamy Pasupathi Y. Yagneswara Rao, Jawahar Farook Ganesan Saravanan, Govindaswamy Bakthavathsalam. Oxidative Stress and Cardiac Biomarkers in Patients with Acute Myocardial Infarction. European Journal of Scientific Research. 2009; 27:275-285.

3. Torun AN, Kulaksizoglu S, Kulaksizoglu M, Pramuk BO, Isbilen E, Tutuncu NB. Serum total antioxidant status and lipid peroxidation marker malondialdehyde levels in overt and subclinical hypothyroidism. Clin Endocrinol. 2009; 70:469-474.

4. Koppenol WH. Names for inorganic radicals (IUPAC recommendations 2000). Pure Appl Chem 2000; 72:437-446.

5. Miller DM, Buettner GR and Aust SD. Transition metals's catalysts of "autoxidation" reactions. Free Radic Biol Med. 1990; 8: 95-108.

6. P. Srilakshmi, MV Bhaskar, K .Rambau, MF Gopinath, GS Reddy. Oxidative stress and cystatin C in coronary artery disease. Indian Streams of Research Journal, 2014; 4: 1-7.

7. Lopaczynski W, Zeisel SH Antioxidants, programmed cell death, and cancer. Nutr Res2001; 21:295-307.

8. Valko M, Rhodes CJ, Moncol J, Izakovic M, Mazur M .Free radicals, metals and antioxidants in oxidative stress-induced cancer. ChemBiol Interact 2006; 160:1-40.

9. Church DF, Pryor WA Free-radical chemistry of cigarette smoke and its toxicological implications. Environ Health Perspect1985; 64:111-126.

10. Riley PA Free radicals in biology: oxidative stress and the effects of ionizing radiation. Int J RadiatBiol1994; 65:27-33.

11. Afanas'ev IB. Competition between superoxide and hydrogen peroxide signaling in heterolytic enzymatic processes. Med Hypotheses. 2006; 66:1125-1128.

12. Halliwell, B. Free radicals, antioxidants and human disease: curiosity, cause, or consequences? Lancet. 1994; 344:721-724.

13. Salvemini D, and Cuzzocrea, S. Therapeutic potential of superoxide dismutase mimetics as therapeutic agents in critical care medicine. Crit. Care Med.2003; 31: (Suppl): S29-S38.

14. Becker, L.B. New concepts in reactive oxygen species and cardiovascular reperfusion physiology. Cardiovasc. Res. 2004; 61: 461-470. 


\section{ORIGINAL ARTICLE}

15. Casalone R, Granata P, Minelli E, P. Portentoso, A. Giudici, R. Righi.P. Castelli, A. Socrate, B. Frigerio. Cytogenic analysis reveals clonal proliferation of smooth muscle cells in atherosclerotic plaques. Hum Genet. 1991; 87:139-143.

16. Jean-Claude Tardif, Oxidative stress and coronary heart disease. Cardiology rounds 2003; 7:1-6.

17. Loeper, J, Goy, J, Rozenstajin, L, Bedu, O, and Moisson P. Lipid peroxidation and protective enzymes during myocardial infarction. Clin Chim Acta.1991; 15:119-125.

18. Neela Patil, Vishwas Chavan, N.D.Karnik Antioxidant status in patients with acute myocardial infarction. Indian Journal of Clinical Biochemistry. 2007; 22:45-51.

19. Giselli, a, Serafini, M, Natella, F, and Scaccini, C. Total antioxidant capacity as a tool assesses redox status: critical view and experimental data. Free Rad. Biol. Med. 2000; 29:1106-1114.

20. Juan J. Hicks, Daniel H. Montes-Cortes, Maria P. Cruz-Dominguez, Roberto Medina-Santillan3, Ivonne M. Olivares Corichi. Antioxidants decrease reperfusion induced arrhythmias in myocardial infarction with ST-elevation. Frontiers in Bioscience. 2007; 12:2029-2037.

21. Palanisamy Pasupathi Y. Yagneswara Rao, Jawahar Farook Ganesan Saravanan, Govindaswamy Bakthavathsalam .0xidative Stress and Cardiac Biomarkers in Patients with Acute Myocardial Infarction. European Journal of Scientific Research. 2009; 27:275-285.

22. Heitzer T, Schlinzig T, Krohn K, Meinertz T, Münzel T. Endothelial dysfunction, oxidative stress, and risk of cardiovascular events in patients with coronary artery disease. Circulation. 2001; 104:2673-2678.

23. Brid NS, Raju UR, Kamat P; Initial ECG as a diagnostic tool for identification of low risk patients with chest pain. RRJMHS, 2014; 3: 111-114.

24. Stephen W. Smith, Wayne Whitwam. Acute Coronary Syndromes: Emerg Med Clin N Am. 2006; 24: 53-89.

25. KJ Raihanathul Misiriya, N Sudhayakumar, S Abdul Khadar, Raju George,VL Jayaprakash, Joseph M Pappachan. The Clinical Spectrum of Acute Coronary Syndromes: Experience from a Major Center in Kerala. JAPI. 2009; 57:.377-383.

26. Ali Movahed, Dariush Iranpour, Iraj Nabipour, Mojtaba Jafari, Samad Akbarzadeh, Majid Assadi, Kamran Mirzaei and Najmeh Hagian. Plasma malondialdehyde, bilirubin, homocysteine and total antioxidant capacity in patients with angiographically defined coronary artery disease. African Journal of Biotechnology. 2012; 12: 3187- 3191.

27. Murat Aydın, Yusuf Selcoki, Yunus Nazl, Necmettin Çolak, Kadir Serkan Yalçın, Metin Canbal, Bora Demirçelik, Ramazan Yiğitoğlu, Beyhan Eryonucu. Relationship between total antioxidant capacity and the severity of coronary artery disease. Journal of clinical and experimental investigations. 2012; 3: 22-28.

28. Viviana Cavalca, Giuliana Cighetti, Fabrizia Bamonti Alessandro Loaldi, Luana Bortone, Cristina Novembrino, Michela De Franceschi, Romualdo Belardinelli, and Maurizio D. Guazzi. Oxidative stress and homocysteine in coronary artery disease. Clinical chemistry. 2001; 47:887-892.

29. Kyung-Hyun Cho, Dong-Gu Shin, Suk-Hwan Baek and Jae-Ryong Kim. Myocardial infarction patients show altered lipoprotein properties and functions when compared with stable angina pectoris patients. Experimental and molecular medicine. 2009; 41: 67-76.

30. Madhur Gupta and Suresh Chari. Proxidant and antioxidant status in patients of type II diabetes mellitus with IHD. Indian Journal of Clinical Biochemistry. 2006; 21: 118-122.

31. Neela Patil, Vishwas Chavan, N.D.Karnik. Antioxidant status in patients with acute myocardial infarction. Indian journal of clinical biochemistry. 2007; 22: 45-51. 


\section{ORIGINAL ARTICLE}

32. Margarete Dulce Bagatini, Caroline Curry Martins, Vanessa Battisti, Diogo Gasparetto, Cintia Saydelles da Rosa, Roselia Maria Spanevello, Mushtaq Ahmed, Roberta Schmatz, Maria Rosa Chitolina Schetinger, Vera Maria Morsch. Oxidative stress versus antioxidant defenses in patients with acute myocardial infarction. Heart Vessels. 2011; 26:55-63.

33. Mudassir Ahmad Khan, Abdul Baseer. Increased Malondialdehyde levels in Coronary Heart Disease. JPMA. 2000; 50:261-267.

34. Stocker R, Keaney JF Jr. New insights on oxidative stress in the artery wall. J Thromb and Haemost. 2005; 3: 1825-1834.

35. Antoniades C, Tousoulis D, Stefanadis C, et al. Effect of endothelial nitric oxide synthase gene polymorphisms on oxidative stress, inflammatory status and coronary atherosclerosis:an example of transient phenotype. J Am CollCardiol. 2007; 49: 1226-1226.

36. Vepa S, Scribner WM, Parinandi NL, et al. Hydrogen peroxide stimulates tyrosine phosphorylation of focal adhesion kinase in vascular endothelial cells. Am J Physiol. 1999; 277:L150-L158.

37. Gozin A, Franzini E, Andrieu V, et al. Reactive oxygen species activate focal adhesion kinase, paxillin and p130cas tyrosine phosphorylation in endothelial cells. Free Radic BiolMed. 1998; 25:1021-1032.

38. Madamanchi NR, Vendrov A, Runge MS. Oxidative stress and vascular disease. Arterioscler Thromb Vasc Biol. 2005; 25: 29-38.

39. Lum H, Roebuck KA. Oxidant stress and endothelial cell dysfunction. Am J Physiol Cell Physiol. 2001; 280: C719-C741.

40. Fuster V, Lewis A. Conner Memorial Lecture: Mechanisms leading to myocardial infarction: insights from studies of vascular biology. Circulation. 1994; 90: 2126-2146.

\section{AUTHORS:}

1. P. Srilakshmi

2. D. Swetha

3. K. Rambabu

PARTICULARS OF CONTRIBUTORS:

1. Associate Professor, Department of Biochemistry, Mamata Medical College.

2. Post Graduate, Department of General Medicine, Mamata Medical College.

FINANCIAL OR OTHER

COMPETING INTERESTS: None
3. Professor and HOD, Department of Biochemistry, Mamata Medical College.

\section{NAME ADDRESS EMAIL ID OF THE CORRESPONDING AUTHOR:}

Dr. P. Srilakshmi, Mamata Medical College, Khammam-507002, Telangana State.

E-mail: sri.biochemistry@gmail.com

Date of Submission: 06/10/2015.

Date of Peer Review: 07/10/2015.

Date of Acceptance: 17/10/2015.

Date of Publishing: 28/10/2015. 